\title{
Serum Potassium Levels and Mortality in Hemodialysis Patients: A Retrospective Cohort Study
}

\author{
Akeem A. Yusuf ${ }^{a}$ Yan Hu $^{a}$ Bhupinder Singh ${ }^{c}$ José A. Menoyo ${ }^{c}$ \\ James B. Wetmore ${ }^{a, b}$ \\ ${ }^{a}$ Chronic Disease Research Group, Minneapolis Medical Research Foundation, and ${ }^{\text {b}}$ Division of Nephrology, Hennepin \\ County Medical Center, Minneapolis, Minn., and ' ZS Pharma Inc., Astra Zeneca Group, San Mateo, Calif., USA
}

\section{Key Words}

End-stage renal disease $\cdot$ Hemodialysis $\cdot$ Hyperkalemia .

Mortality · Potassium

\begin{abstract}
Background: Hyperkalemia is common in patients receiving maintenance hemodialysis. However, few studies have examined the association between serum potassium level and mortality. Methods: This study used annual cohorts of hemodialysis patients during 2007-2010. To determine hyperkalemia prevalence, monthly hyperkalemia was defined as serum potassium level $\geq 5.5 \mathrm{mEq} /$; prevalence was calculated as a ratio of hyperkalemia episodes to follow-up time, reported separately by long and short interdialytic interval. To determine the impact of hyperkalemia on mortality, patients in the 2010 cohort were followed from first potassium measurement until death or a censoring event; hyperkalemia was defined, sequentially, by potassium levels 5.5-6.0 $\mathrm{mEq} / \mathrm{l}$ at $0.1 \mathrm{mEq} / \mathrm{l}$ intervals. Time-dependent Cox proportional hazards modeling was used to estimate the association between hyperkalemia and mortality. Results: The 4 annual cohorts ranged from 28,774 to 36,888 patients. Mean age was approximately 63 years, about $56 \%$ were men, $51 \%$ were white and $44 \%$ had end-stage renal disease caused by diabetes. Hyperkalemia prevalence was consistently estimated at 16.3-16.8 events per 100 patient-months. Preva-
\end{abstract}

lence on the day after the long interdialytic interval was 2.02.4 times as high as on the day after the short interval. Hyperkalemia, when defined as serum potassium $\geq 5.7 \mathrm{mEq} / \mathrm{l}$, was associated with all-cause mortality (adjusted hazards ratio (AHR) 1.13, 95\% Cl 1.01-1.28, $\mathrm{p}=0.037$, vs. $<5.7 \mathrm{mEq} / \mathrm{l}$ ) after adjustment. AHRs increased progressively as the hyperkalemia threshold increased, reaching 1.37 (95\% Cl 1.16$1.62, p<0.0001$ ) for $\geq 6.0 \mathrm{mEq} / \mathrm{l}$. Conclusions: The long interdialytic interval was associated with increased likelihood of hyperkalemia. Hyperkalemia was associated with allcause mortality beginning at serum potassium $\geq 5.7 \mathrm{mEq} / \mathrm{l}$; mortality risk estimates increased ordinally through $\geq 6.0$ $\mathrm{mEq} / \mathrm{l}$, suggesting a threshold at which serum potassium becomes substantially more dangerous.

๑) 2016 S. Karger AG, Basel

\section{Introduction}

Hyperkalemia, a potentially life-threatening condition associated with ventricular arrhythmias and sudden cardiac arrest [1-5], is common in patients with chronic kidney disease, particularly those receiving maintenance dialysis. Maintenance hemodialysis patients, most of whom have little to no residual renal function, rely almost exclusively on the intermittent potassium clearance provided by hemodialysis, supplemented in small measure by gut

\section{KARGER}

E-Mail karger@karger.com

www.karger.com/ajn
(C) 2016 S. Karger AG, Basel

0250-8095/16/0443-0179\$39.50/0
Akeem A. Yusuf, $\mathrm{PhD}$

Chronic Disease Research Group

Minneapolis Medical Research Foundation, 914 South 8th Street

Suite S2.100, Minneapolis, MN 55404 (USA)

E-Mail yusuf054@umn.edu 
potassium excretion [6]. Additional risks for hyperkalemia include non-adherence to dietary restrictions, metabolic acidosis, anemia requiring red blood cell transfusions and alterations in the intracellular/extracellular potassium distribution. As a result, many hemodialysis patients regularly experience wide variations in serum potassium levels. Because hyperkalemia itself and the rapid shifts in potassium associated with hemodialysis sessions appear to confer risk [7-9], treatment of hyperkalemia is fraught with clinical challenges, as well-intentioned attempts to treat persistently hyperkalemic patients by increasing potassium clearance using low-potassium dialysate may actually increase risk of death $[10,11]$.

Given the high risk of hyperkalemia for hemodialysis patients, several observational studies have examined the association between hyperkalemia and adverse events [12-15]. While hyperkalemia has been repeatedly associated with sudden death and other adverse events, there is no universally accepted definition of significant hyperkalemia; studies employ various thresholds such as 5.0, 5.5 or $6.0 \mathrm{mEq} / 1$ [16-23]. As such, the precise relationship between hyperkalemia and death of patients on hemodialysis is uncertain.

To better understand the association between hyperkalemia and mortality in patients receiving maintenance hemodialysis, we designed a large retrospective cohort study using patient level data on serum potassium levels linked with outcomes ascertained from billing claims data. Our objectives were to (1) ascertain the prevalence of hyperkalemia, (2) explore how the length of the interdialytic interval was associated with likelihood of hyperkalemia and (3) determine the relationship between hyperkalemia and mortality. By varying the definition of hyperkalemia, we specifically sought to determine whether there was a threshold at which potassium is associated with a marked increase in either all-cause or cause-specific mortality. Characterizing the relationship between the degree of hyperkalemia and the risk of adverse outcomes may help provide practical guidance to nephrologists and other healthcare providers working in dialysis settings.

\section{Materials and Methods}

\section{Data Sources}

Data for these analyses were derived from the United States Renal Data System (USRDS), a national system that collects data on virtually all patients undergoing maintenance dialysis in the US and a large dialysis organization (LDO). The LDO is a major dialysis provider with a substantial national presence. We received standard patient records from the USRDS including data on de- mographics and comorbid conditions at the time of dialysis commencement, and on inpatient and outpatient medical claims paid by Medicare. Medicare is a federally funded program to which nearly all adults with end-stage renal disease (ESRD) are entitled [24]. USRDS data were linked to the LDO data through an agreement with the relevant project officers of the National Institute of Diabetes and Digestive and Kidney Diseases.

\section{Study Cohort and Design}

This was a retrospective follow-up study of hemodialysis patients dialyzing between 2007 and 2010. Two separate studies were undertaken: an analysis of the frequency of hyperkalemia and an analysis of the association of hyperkalemia with death.

\section{Hyperkalemia Prevalence Analysis}

We identified yearly cohorts (2007-2010) of prevalent hemodialysis patients aged $\geq 18$ years who were continuously enrolled in Medicare parts A and B from July 1 of the preceding year through January 31 of the cohort year, received at least 6 hemodialysis treatment sessions in December of the preceding year, had at least 1 recorded serum potassium measurement in January of the cohort year and had non-missing dialysate potassium concentration records for hemodialysis treatments received in December of the preceding year. The index exposure was the first serum potassium value in January of the cohort year. Exclusion criteria included fewer than 6 hemodialysis sessions in December of the preceding year, change in prescribed dialysate potassium concentration between December 1 of the preceding year and the date of the index exposure in January of the cohort year, and absence of a stable thrice-weekly hemodialysis schedule.

On a monthly basis, hyperkalemia was defined as a serum potassium concentration $\geq 5.5 \mathrm{mEq} / \mathrm{l}$. Blood samples were drawn during routine hemodialysis sessions at the LDO and were measured in a central laboratory within $24 \mathrm{~h}$. Blood draws for serum potassium measurements typically occur once monthly but can occur more frequently. If multiple measurements occurred in any given month, hyperkalemia was determined using the record with the highest serum potassium concentration. Hyperkalemia prevalence was calculated as the cumulative number of monthly episodes divided by cumulative follow-up time in months and expressed as number of high-potassium events per 100 patient-months.

Hyperkalemia prevalence was also reported separately by long and short interdialytic interval. The hemodialysis schedule was defined as Monday-Wednesday-Friday (MWF) or Tuesday-Thursday-Saturday (TThS). The day after the long 3-day interval between sessions (long interdialytic interval) was defined as Monday for patients on a MWF schedule and as Tuesday for patients on a TThS schedule [8]. Thus, for patients on a MWF schedule, hyperkalemia events occurring on Monday were attributed to a long interdialytic interval, and on other days to the short interdialytic interval; Tuesday was treated analogously.

\section{Mortality Analyses}

These analyses were limited to patients included in the $2010 \mathrm{co}-$ hort. We defined hyperkalemic events as episodes of hyperkalemia ascertained from measured serum potassium laboratory values; we used several definitions of hyperkalemia, as described below. The key exposure variable in these analyses was determined from monthly serum potassium measurements; the index date for each patient was the date of the first serum potassium measurement in 
January 2010. Patients were followed from the index date until the earliest of death, kidney transplant, change in dialysis modality, change in dialysate potassium concentration, discontinuation of Medicare enrollment, loss to follow-up or December 31, 2010 (study end). Because each patient could (and almost always did) have multiple exposure assessments during the follow-up period, the exposure variable (hyperkalemic event) was operationalized as a dichotomous, time-varying (monthly) covariate with 2 levels (high versus normal serum potassium level), defined, sequentially, by serum potassium levels of $5.5-6.0 \mathrm{mEq} / \mathrm{l}$ at successive $0.1 \mathrm{mEq} / \mathrm{l}$ intervals.

\section{Covariates}

Demographic and clinical variables were drawn from the Centers for Medicare and Medicaid Services (CMS) Medical Evidence Report (form CMS-2728) completed upon dialysis initiation and supplemented by Medicare claims. Variables included age, sex, race by ethnicity, body mass index, cause of ESRD and comorbid conditions. Initial conditions examined were diabetes, coronary artery disease, congestive heart failure, cerebrovascular disease and peripheral vascular disease. Comorbid conditions from Medicare claims were defined during the 6-month baseline period (defined as the 6 months preceding the first index date). For each comorbid condition, we required the presence of $\geq 1$ inpatient code or $\geq 2$ outpatient codes $[25,26]$. Cumulative number of hospitalized days was determined from hospital inpatient claims during the baseline period. Dialysate potassium concentration was identified from records of dialysis treatments received in December 2009. Cause of death was defined using the ESRD Death Notification (form CMS-2746).

\section{Statistical Analysis}

Patient characteristics across cohort years were examined using descriptive statistics for continuous and categorical variables. We reported prevalence rates of hyperkalemia overall and stratified by interdialytic interval for each cohort year.

To examine the association between hyperkalemic events and outcomes of interest (all-cause and cardiovascular-specific death, separately), we used time-dependent Cox proportional hazards regression [27]. We created multiple records for each patient, corresponding to the distinct time intervals between ascertainment of consecutive hyperkalemic events. Each such distinct interval represented time during which a patient was continuously at risk for the outcome event, and events could occur only at the end of the interval. We adjusted the regression models for the above mentioned covariates, and for hemodialysis access type, total hospitalization days during the baseline period, and dialysate potassium concentration.

We applied to and received approval from the Human Subjects Research Committee of the Hennepin County Medical Center/ Hennepin Healthcare System, Inc.

\section{Results}

\section{Cohort Characteristics}

For cohort years 2007 through 2010, we identified 28,774-36,888 hemodialysis patients, after application of inclusion and exclusion criteria (fig. 1). Mean age was ap-

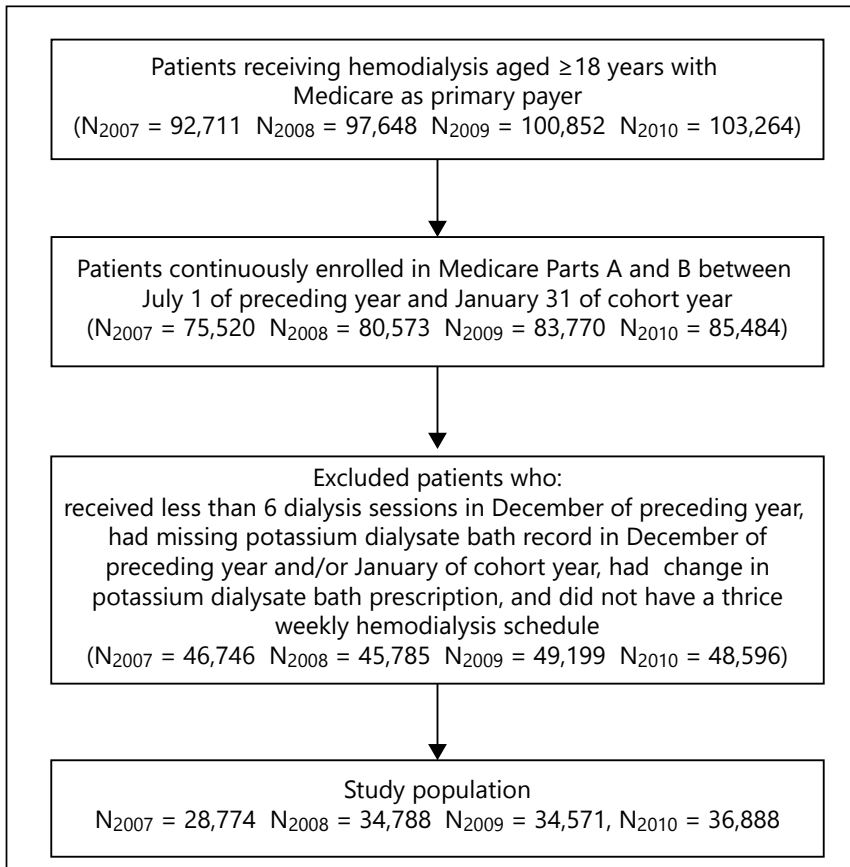

Fig. 1. Sample size of study cohorts, with iterative application of inclusion and exclusion criteria.

proximately 63 years; slightly more than half of patients were white and approximately $56 \%$ were men (table 1 ). Mean dialysis duration was about 5 years. The most common primary cause of ESRD was diabetes, at approximately $44 \%$. Nearly two-thirds $(62.8-65.2 \%)$ of patients were on a MWF hemodialysis schedule. The proportions of patients with potassium bath $\geq 3.0 \mathrm{mEq} / \mathrm{l}$ decreased from 2007 to 2010 , from 17.8 to $11.7 \%$. The proportion on low potassium baths $(<2.0 \mathrm{mEq} / \mathrm{l})$ also decreased, from 14.8 to $10.7 \%$. A potassium bath concentration of $2-<3 \mathrm{mEq} / \mathrm{l}$ was the most common in each year studied.

\section{Hyperkalemia Prevalence}

Overall, hyperkalemia prevalence was consistent at 16.3-16.8 events per 100 patient-months (table 2). Prevalence of hyperkalemia on the day after the long interdialytic interval was 58.7-62.9 per 100 patient-months. In contrast, prevalence on the day after the short interdialytic interval was $26.2-28.8$ per 100 patient-months. Hyperkalemia was 2.0-2.4 times more likely on the day after the long interdialytic interval than on the day after the short interval. Because few hyperkalemia events were recorded on days without dialysis, hyperkalemia prevalence on those days was negligible (0.04-0.07 per 100 patientmonths). 
Table 1. Characteristics of annual cohorts of hemodialysis patients

\begin{tabular}{|c|c|c|c|c|}
\hline & \multicolumn{4}{|l|}{ Cohort year } \\
\hline & 2007 & 2008 & 2009 & 2010 \\
\hline Cohort size, $\mathrm{n}$ & 28,774 & 34,788 & 34,571 & 36,888 \\
\hline Age, years, mean $\pm S^{a}$ & $62.8 \pm 14.7$ & $62.9 \pm 14.7$ & $62.7 \pm 14.7$ & $62.9 \pm 14.6$ \\
\hline \multicolumn{5}{|l|}{ Age, years, $\%$} \\
\hline $18-44$ & 12.7 & 12.6 & 12.8 & 12.1 \\
\hline $45-64$ & 39.3 & 39.1 & 39.7 & 40.3 \\
\hline $65-74$ & 25.2 & 25.3 & 24.9 & 24.8 \\
\hline$\geq 75$ & 22.8 & 23.0 & 22.6 & 22.8 \\
\hline Female, $\%$ & 45.2 & 44.3 & 43.8 & 44.0 \\
\hline \multicolumn{5}{|l|}{ Race, \% } \\
\hline White & 50.3 & 51.2 & 51.1 & 51.7 \\
\hline Black & 43.8 & 43.1 & 42.8 & 42.2 \\
\hline Other & 5.9 & 5.8 & 6.1 & 6.1 \\
\hline Dialysis duration, years, mean $\pm \mathrm{SD}^{\mathrm{a}}$ & $5.0 \pm 4.5$ & $5.0 \pm 4.5$ & $5.1 \pm 4.7$ & $5.2 \pm 4.7$ \\
\hline \multicolumn{5}{|l|}{ Primary cause of ESRD, \% } \\
\hline Diabetes & 43.6 & 43.8 & 44.2 & 44.5 \\
\hline Hypertension & 30.1 & 30.2 & 30.2 & 30.2 \\
\hline Glomerulonephritis & 10.9 & 10.4 & 10.1 & 9.8 \\
\hline Other cause & 15.5 & 15.6 & 15.5 & 15.5 \\
\hline \multicolumn{5}{|l|}{ Access type, \% } \\
\hline Arteriovenous fistula & 3.2 & 5.9 & 8.1 & 10.1 \\
\hline Graft & 1.3 & 2.1 & 2.5 & 2.7 \\
\hline Catheter & 15.3 & 27.4 & 37.0 & 44.6 \\
\hline Other/unknown & 80.1 & 64.6 & 52.5 & 42.6 \\
\hline Body mass index, $\mathrm{kg} / \mathrm{m}^{2}$, mean $\pm \mathrm{SD}$ & $28.3 \pm 7.5$ & $27.8 \pm 7.2$ & $28.0 \pm 7.2$ & $28.2 \pm 7.2$ \\
\hline$<18.5$ & 9.5 & 3.7 & 3.2 & 3.0 \\
\hline $18.5-<25$ & 32.1 & 36.3 & 35.8 & 35.0 \\
\hline $25-<30$ & 27.4 & 29.9 & 30.3 & 29.8 \\
\hline$\geq 30$ & 31.1 & 30.2 & 30.7 & 32.1 \\
\hline Hospitalized $^{\mathrm{b}}, \%$ & 37.0 & 36.7 & 36.5 & 35.4 \\
\hline Cumulative hospital days ${ }^{\mathrm{c}}$, mean $\pm \mathrm{SD}$ & $11.7 \pm 12.6$ & $11.6 \pm 12.3$ & $11.5 \pm 12.3$ & $11.2 \pm 12.1$ \\
\hline \multicolumn{5}{|l|}{ Comorbid conditions ${ }^{\mathrm{d}}, \%$} \\
\hline Atherosclerotic heart disease & 31.0 & 31.3 & 31.5 & 30.4 \\
\hline Congestive heart failure & 38.1 & 39.1 & 38.7 & 38.0 \\
\hline Cerebrovascular accident & 12.2 & 11.9 & 12.1 & 12.3 \\
\hline Peripheral vascular disease & 21.9 & 22.1 & 22.4 & 22.1 \\
\hline Other cardiac disease & 11.6 & 13.1 & 14.3 & 14.6 \\
\hline COPD & 14.8 & 14.8 & 14.7 & 14.4 \\
\hline Gastrointestinal disorders & 2.7 & 2.7 & 2.7 & 2.5 \\
\hline Liver disease & 1.2 & 1.3 & 1.1 & 1.2 \\
\hline Dysrhythmia & 14.9 & 15.0 & 14.7 & 14.6 \\
\hline Cancer & 6.5 & 6.4 & 6.7 & 6.9 \\
\hline Diabetes & 57.9 & 59.0 & 59.9 & 60.3 \\
\hline \multicolumn{5}{|l|}{ Weekly dialysis schedule ${ }^{\mathrm{d}}, \%$} \\
\hline TThS & 37.2 & 36.1 & 36.3 & 34.8 \\
\hline MWF & 62.8 & 63.9 & 63.7 & 65.2 \\
\hline \multicolumn{5}{|l|}{ Dialysate potassium bath ${ }^{\mathrm{d}}, \mathrm{mEq} / \mathrm{l}, \%$} \\
\hline$<2$ & 14.8 & 11.6 & 11.2 & 10.7 \\
\hline $2-<3$ & 67.4 & 73.9 & 75.8 & 77.7 \\
\hline$\geq 3$ & 17.8 & 14.5 & 12.9 & 11.7 \\
\hline
\end{tabular}

a On index date.

${ }^{b}$ Accessed during the 180 days before the index date.

${ }^{c}$ For hospitalized patients.

${ }^{\mathrm{d}}$ Accessed from claims during the 6 months preceding the index date.

COPD $=$ Chronic obstructive pulmonary disease. 
Table 2. Prevalence of hyperkalemia episodes per 100 patient-months in hemodialysis patients

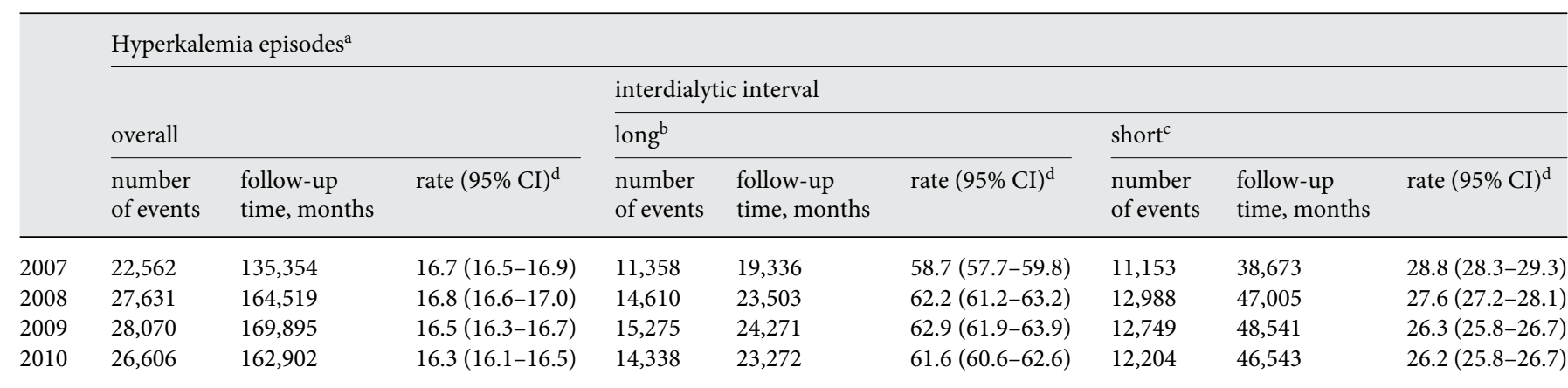

\footnotetext{
${ }^{a}$ Hyperkalemia episode was defined as a serum potassium concentration $\geq 5.5 \mathrm{mEq} / \mathrm{l}$, and was accessed on a monthly basis.

${ }^{\mathrm{b}}$ Calculated based on hyperkalemia episodes identified on the day after the long interdialytic interval.

${ }^{c}$ Calculated based on hyperkalemia episodes identified on the day after the short interdialytic interval.

${ }^{d}$ Rate of hyperkalemia was computed as a ratio of total number of hyperkalemia episodes and cumulative follow-up time; $95 \%$ CI for the rates of hyperkalemia were calculated based on normal approximation.
}

Table 3. Association between elevated serum levels and all-cause and cardiovascular-specific mortality in hemodialysis patients

\begin{tabular}{|c|c|c|c|c|c|c|c|c|}
\hline \multirow{3}{*}{$\begin{array}{l}\text { Serum } \mathrm{K} \text { thresholds } \\
\text { defining hyperkalemia, } \\
\mathrm{mEq} / \mathrm{l}\end{array}$} & \multicolumn{4}{|c|}{ All-cause mortality } & \multicolumn{4}{|c|}{ Cardiovascular-specific mortality } \\
\hline & \multicolumn{2}{|l|}{ unadjusted } & \multicolumn{2}{|l|}{ adjusted $^{\mathrm{a}}$} & \multicolumn{2}{|l|}{ unadjusted } & \multicolumn{2}{|l|}{ adjusted $^{\mathrm{a}}$} \\
\hline & HR $(95 \% \mathrm{CI})^{\mathrm{b}}$ & $\mathrm{p}$ value & HR $(95 \% \mathrm{CI})^{\mathrm{b}}$ & $\mathrm{p}$ value & $\operatorname{HR}(95 \% \mathrm{CI})^{\mathrm{b}}$ & $\mathrm{p}$ value & $\operatorname{HR}(95 \% \mathrm{CI})^{\mathrm{b}}$ & $\mathrm{p}$ value \\
\hline$\geq 5.5$ & $1.00(0.91-1.11)$ & 0.94 & $0.99(0.89-1.09)$ & 0.78 & $1.05(0.91-1.21)$ & 0.55 & $1.00(0.86-1.17)$ & 0.97 \\
\hline$\geq 5.6$ & $1.05(0.94-1.16)$ & 0.42 & $1.03(0.92-1.15)$ & 0.62 & $1.10(0.94-1.29)$ & 0.23 & $1.06(0.90-1.25)$ & 0.49 \\
\hline$\geq 5.7$ & $1.14(1.01-1.28)$ & 0.03 & $1.13(1.01-1.28)$ & 0.04 & $1.12(0.94-1.34)$ & 0.20 & $1.09(0.91-1.31)$ & 0.36 \\
\hline$\geq 6.0$ & $1.34(1.14-1.58)$ & $<0.001$ & $1.37(1.16-1.62)$ & $<0.001$ & $1.29(1.01-1.66)$ & 0.04 & $1.28(0.99-1.64)$ & 0.06 \\
\hline
\end{tabular}

a Adjusted for age, sex, race, dialysis duration, primary cause of ESRD, dialysis access type, body mass index, baseline cumulative hospital days, baseline cardiovascular hospitalization, dialysate potassium bath and comorbid conditions.

${ }^{\mathrm{b}}$ Corresponds to the mortality risk for elevated serum potassium relative to normal potassium in hemodialysis patients. For example, for serum $\mathrm{K}$ threshold of 5.5, comparison groups are those with serum $\mathrm{K} \geq 5.5 \mathrm{vs}$. $<5.5$. Similarly, for serum $\mathrm{K}$ threshold of $5.6 \mathrm{mEq} / \mathrm{l}$, comparison groups are those with serum $\mathrm{K} \geq 5.6$ vs. $<5.6$

$\mathrm{K}=$ Potassium

Hyperkalemia prevalence appeared to decrease with age; for example, in 2010, 18.7 events per 100 patientmonths occurred among patients aged 18-44 years and 12.6 among those aged $\geq 75$ years (online suppl. table S1; for all online suppl. material, see www.karger.com/ doi/10.1159/000448341). Hyperkalemia was more frequent in white than in black patients (18.9 vs. 12.2 per 100 patient-months) and in patients on low potassium dialysate baths $(<2 \mathrm{mEq} / \mathrm{l})$, and increased with dialysis duration.

\section{Mortality Analysis}

During a mean follow-up of $273 \pm 113$ days (equivalent to $0.75 \pm 0.31$ years), $10.2 \%$ of patients $(\mathrm{n}=3,753)$ died, $43.1 \%(4.3 \%$ of the total, $n=1,604)$ from cardiovascular causes. Censoring occurred for 1 patient who underwent kidney transplant, $2.9 \%(\mathrm{n}=1,082)$ who changed dialysis modality, $7.7 \%(\mathrm{n}=2,832)$ who discontinued Medicare enrollment and $23.4 \%(\mathrm{n}=8,633)$ who changed dialysate potassium concentration; $55.8 \%(n=20,587)$ were censored alive at study end.

All-cause mortality hazard ratios (HRs) for high relative to normal potassium when hyperkalemia was defined as a serum potassium level of $\geq 5.5 \mathrm{mEq} / \mathrm{l}$ were $1.00(95 \%$ CI 0.91-1.11) and 0.99 (95\% CI 0.89-1.09) in unadjusted and adjusted analyses, respectively (table 3 ). As the serum potassium concentration threshold for defining hyperkalemia increased by $0.1 \mathrm{mEq} / \mathrm{l}$ increments, the unadjusted and adjusted HRs (AHRs) for all-cause mortality, which 
remained generally similar to each other throughout, increased monotonically in both unadjusted and adjusted models. The AHR for all-cause mortality became statistically significant when hyperkalemia was defined as serum potassium $\geq 5.7 \mathrm{mEq} / \mathrm{l}(1.13,95 \% \mathrm{CI} 1.01-1.28, \mathrm{p}=0.04)$, increasing to $1.29(95 \% \mathrm{CI} 1.12-1.50, \mathrm{p}<0.001)$ at $\geq 5.9$ $\mathrm{mEq} / \mathrm{l}$ and $1.37(95 \% \mathrm{CI} 1.13-1.62, \mathrm{p}<0.001)$ at $\geq 6.0$ $\mathrm{mEq} / \mathrm{l}$.

As serum potassium concentration thresholds for defining hyperkalemia increased by $0.1 \mathrm{mEq} / 1$ increments, unadjusted and AHRs for cardiovascular mortality, which also remained generally similar to each other throughout, increased monotonically in unadjusted and adjusted models (table 3). The unadjusted HR for cardiovascular mortality became statistically significant when hyperkalemia was defined as serum potassium $\geq 6.0 \mathrm{mEq} / 1$ (1.29, $95 \%$ CI 1.01-1.66, $\mathrm{p}=0.04)$. Online supplementary tables S2 and S3 show full results of the adjusted models.

\section{Discussion}

Despite substantial improvement in the mean lifespan of patients receiving maintenance hemodialysis [28], sudden death, most of which is thought be arrhythmic in nature, remains a major threat $[29,30]$. Accordingly, previous studies have attempted to link hyperkalemia to sudden cardiac death directly [13-15] or circumstantially, but compellingly, via the interdialytic interval $[8,31]$. To better understand this phenomenon and to fill gaps in the putative chain of causality, we investigated several different but related issues. We sought to determine whether there was evidence of a graded association between serum potassium level and mortality, and to ascertain whether potassium levels may be higher after the long interdialytic interval. We found that increased serum potassium levels were, as expected, associated with increased risk of all-cause mortality with $5.7 \mathrm{mEq} / \mathrm{l}$ as a critical threshold, and that hyperkalemia appeared to be substantially more common after the long interdialytic interval. These findings, in conjunction with previous work [8, 13-15, 31], suggest that hyperkalemia may be the mechanism by which the long interdialytic interval is associated with death.

While previous observational studies have demonstrated that hyperkalemia is associated with mortality, various definitions of hyperkalemia have been employed. For example, Iseki et al. [15] defined hyperkalemia as a serum potassium concentration of $\geq 5.5 \mathrm{mEq} / \mathrm{l}$ and reported increased risk of death relative to a baseline con- centration of $<3.5 \mathrm{mEq} / \mathrm{l}$. Kovesdy et al. [14], in a large observational study of a contemporary cohort of hemodialysis patients, showed that a serum potassium concentration of $\geq 5.6 \mathrm{mEq} / \mathrm{l}$ was associated with increased risk of all-cause and cardiovascular death. In an investigation of cardiac arrest and sudden death in dialysis units, Karnik et al. [11] defined hyperkalemia as serum potassium $\geq 6.0 \mathrm{mEq} / \mathrm{l}$.

The present study, which sought to determine the nature of the relationship between serum potassium level and risk of death, enriches this understanding and therefore could have both practical and theoretical relevance. In our study population, we identified a graded association between hyperkalemia and mortality and found that the risk becomes statistically significant at a potassium level of approximately $5.7 \mathrm{mEq} / \mathrm{l}$. This may have clinical implications, as it could be a threshold at which clinicians should consider taking action or at which protocols designed to safeguard patients could be employed. The graded association also establishes the 'gain' in the clinical signal, permitting approximate quantification of the increased risk associated with, for example, a serum potassium level of $6.0 \mathrm{mEq} / \mathrm{l}$ compared with a normal level. This association could also inform the design of clinical trials testing interventions on hyperkalemia, and permit initial inferences to be made on trial effect sizes and power.

The finding that hyperkalemia becomes markedly more common after the long interdialytic interval, while not intuitively surprising, has not, to our knowledge, been conclusively demonstrated. This finding also has both clinical and theoretical implications. It suggests that interventions to prevent hyperkalemia and resultant sudden cardiac death might most appropriately be employed if the interdialytic interval is expected to be longer than $48 \mathrm{~h}$. It also provides an estimate of how hyperkalemia occurrence could be reduced if all interdialytic intervals were reduced to $48 \mathrm{~h}$ or less. From a theoretical perspective, it helps establish a putative link between hyperkalemia and the increased risk of death associated with the long interdialytic interval $[8,26]$.

We found no association between hyperkalemia and cardiovascular mortality. This was unexpected because hyperkalemia can induce life-threatening cardiac electrophysiologic alterations [32]. Indeed, several studies have reported an association between hyperkalemia and increased risk of lethal cardiac arrhythmias in dialysis patients $[13,14]$. However, this phenomenon is not uncommon in observational studies [33]. One possible explanation is misclassification: cardiovascular events as causes of death are not adjudicated by the USRDS, our source of 
data. Importantly, however, the pattern of point estimates for cardiovascular mortality closely mirrored the pattern for all-cause mortality, suggesting that the reason for lack of statistical significance may have been power.

Our study has important limitations. First, because we used a retrospective observational design, associations can never be determined to be causal. Additionally, as with all observational studies, confounding is likely to be present. While we considered and adjusted for select known confounders (e.g., demographic factors, clinical factors such as comorbid conditions and treatment factors such as dialysate potassium bath), we were unable to account for unknown and unmeasured factors that may predispose patients to adverse clinical outcomes. However, it is reassuring that the adjustments made attenuated the observed effect estimates only modestly, suggesting the fairly robust findings. Additionally, we did not seek to model factors associated with hyperkalemia, which would be an important exercise for generating hypotheses about factors that could be targeted for potential interventions.

In conclusion, we found that hyperkalemia was associated with an increased risk of all-cause mortality after adjustment for other factors, but not cardiovascular-related mortality. The threshold analysis, in which successively greater serum potassium thresholds were used, revealed a relatively constant ordinal increase in risk and demonstrated statistical significance at a potassium level of $5.7 \mathrm{mEq} / \mathrm{l}$. That the threshold of hyperkalemia associated with mortality was relatively high may be due to adaptive mechanisms present in maintenance hemodialysis patients, many of whom seem able to tolerate higher potassium levels than individuals with intact kidney function. The long interdialytic interval was associated with substantially greater likelihood of hyperkalemia than the short interval, strengthening the case that hyperkalemia is the mechanism by which the long interdialytic interval is associated with mortality. These findings raise the possibility that improved management of hyperkalemia in patients receiving hemodialysis may lead to reduced mortality, particularly during the long interdialytic interval. Future work studying how hyperkalemia, potassium variability and changes in potassium levels contribute to mortality, especially sudden cardiac death, is needed.

\section{Acknowledgments}

The authors thank Chronic Disease Research Group colleague Nan Booth, MSW, MPH, ELS, for manuscript editing. The authors also thank Alex Yang, MD, for helpful discussions about the project.

\section{Disclosure Statement}

This work was supported by a grant from ZS Pharma Inc., San Mateo, Calif., USA. The interpretation and reporting of these data are the responsibility of the authors, who retain final authority over manuscript content. Dr. A.A. Yusuf, Ms. Y. Hu and Dr. J.B. Wetmore report no conflicts of interest. Dr. J. Menoyo and Dr. B. Singh are employees of ZS Pharma Inc.

\section{References}

1 Brophy DF, Gehr TWB: Disorders of potassium and magnesium homeostasis; in DiPiro JT, et al (eds): Pharmacotherapy: A Pathophysiologic Approach, ed 6. New York, McGraw-Hill, 2005, pp 972-977.

2 Mandal AK: Hypokalemia and hyperkalemia. Med Clin North Am 1997;81:611-639.

3 Weiner ID, Wingo CS: Hyperkalemia: a potential silent killer. J Am Soc Nephrol 1998;9: 1535-1543.

4 Genovesi S, Valsecchi MG, Rossi E, Pogliani D, Acquistapace I, De Cristofaro V, Stella A, Vincenti A: Sudden death and associated factors in a historical cohort of chronic haemodialysis patients. Nephrol Dial Transplant 2009;24:2529-2536.

5 Herzog CA, Mangrum JM, Passman R: Sudden cardiac death and dialysis patients. Semin Dial 2008;21:300-307.

6 Ahmed J, Weisberg LS: Hyperkalemia in dialysis patients. Semin Dial 2001;14:348356.
7 Bleyer AJ, Russell GB, Satko SG: Sudden and cardiac death rates in hemodialysis patients. Kidney Int 1999;55:1553-1559.

8 Foley RN, Gilbertson DT, Murray T, Collins AJ: Long interdialytic interval and mortality among patients receiving hemodialysis. $\mathrm{N}$ Engl J Med 2011;365:1099-1107.

9 Jadoul M, Thumma J, Fuller DS, Tentori F, Li $\mathrm{Y}$, Morgenstern H, Mendelssohn D, Tomo T, Ethier J, Port F, Robinson BM: Modifiable practices associated with sudden death among hemodialysis patients in the dialysis outcomes and practice patterns study. Clin J Am Soc Nephrol 2012;7:765-774.

10 Pun PH, Lehrich RW, Honeycutt EF, Herzog CA, Middleton JP: Modifiable risk factors associated with sudden cardiac arrest within hemodialysis clinics. Kidney Int 2011;79:218-227.

11 Karnik JA, Young BS, Lew NL, Herget M, Dubinsky C, Lazarus JM, Chertow GM: Cardiac arrest and sudden death in dialysis units. Kidney Int 2001;60:350-357.
12 Hayes J, Kalantar-Zadeh K, Lu JL, Turban S, Anderson JE, Kovesdy CP: Association of hypo- and hyperkalemia with disease progression and mortality in males with chronic kidney disease: the role of race. Nephron Clin Pract 2012;120:c8-c16.

13 Torlén K, Kalantar-Zadeh K, Molnar MZ, Vashistha T, Mehrotra R: Serum potassium and cause-specific mortality in a large peritoneal dialysis cohort. Clin J Am Soc Nephrol 2012;7:1272-1284.

14 Kovesdy CP, Regidor DL, Mehrotra R, Jing J, McAllister CJ, Greenland S, Kopple JD, Kalantar-Zadeh K: Serum and dialysate potassium concentrations and survival in hemodialysis patients. Clin J Am Soc Nephrol 2007;2: 999-1007.

15 Iseki K, Uehara H, Nishime K, Tokuyama K, Yoshihara K, Kinjo K, Shiohira Y, Fukiyama $\mathrm{K}$ : Impact of the initial levels of laboratory variables on survival in chronic dialysis patients. Am J Kidney Dis 1996;28:541-548. 
16 Nyirenda MJ, Tang JI, Padfield PL, Seckl JR: Hyperkalemia. BMJ 2009;339:b4114.

17 Ahee $\mathrm{P}$, Crowe A: The management of hyperkalemia in the emergency department. J Accid Emerg Med 2000;17:188-191.

18 Alfonzo AV, Isles C, Geddes C, Deighan C: Potassium disorders - clinical spectrum and emergency management. Resuscitation 2006; 70:10-25.

19 Ahuja TS, Freeman D Jr, Mahnken JD, Agraharkar M, Siddiqui M, Memon A: Predictors of the development of hyperkalemia in patients using angiotensin-converting enzyme inhibitors. Am J Nephrol 2000;20:268-272.

20 Rossignol P, Dobre D, Gregory D, Massaro J, Kiernan M, Konstam MA, Zannad F: Incident hyperkalemia may be an independent therapeutic target in low ejection fraction heart failure patients: insights from the HEAAL study. Int J Cardiol 2014;173:380-387.

21 Kuijvenhoven MA, Haak EA, GombertHandoko KB, Crul M: Evaluation of the concurrent use of potassium-influencing drugs as risk factors for the development of hyperkalemia. Int J Clin Pharm 2013;35:1099-1104.

22 Raebel MA, Smith ML, Saylor G, Wright LA, Cheetham C, Blanchette CM, Xu S: The positive predictive value of a hyperkalemia diagnosis in automated health care data. Pharmacoepidemiol Drug Saf 2010;19:1204-1208.
23 Kovesdy CP: Management of hyperkalemia in chronic kidney disease. Nat Rev Nephrol 2014; 10:653-662.

24 Centers for Medicare and Medicaid Services: What is Medicare? https://www.medicare. gov/sign-up-change-plans/decide-how-toget-medicare/whats-medicare/what-ismedicare.html (accessed June 20, 2016).

25 Liu J, Huang Z, Gilbertson DT, Foley RN, Collins AJ: An improved comorbidity index for outcome analyses among dialysis patients. Kidney Int 2010;77:141-151.

26 Hebert PL, Geiss LS, Tierney EF, Engelgau MM, Yawn BP, McBean AM: Identifying persons with diabetes using Medicare claims data. Am J Med Qual 1999;14:270-277.

27 Allison PD: Survival Analysis Using SAS: A Practical Guide, ed 2. Cary, SAS Institute Inc., National Institutes of Health, National Institute of Diabetes and Digestive and Kidney Diseases, 2015, pp 260-281.

28 US Renal Data System: 2015 USRDS Annual Data Report: Epidemiology of Kidney Disease in the United States. Bethesda, National Institutes of Health, National Institute of Diabetes and Digestive and Kidney Diseases, 2015.
29 Collins AJ, Foley RN, Chavers B, Gilbertson D, Herzog C, Ishani A, Johansen K, Kasiske BL, Kutner N, Liu J, St Peter W, Guo H, Hu Y, Kats A, Li S, Li S, Maloney J, Roberts T, Skeans M, Snyder J, Solid C, Thompson B, Weinhandl E, Xiong H, Yusuf A, Zaun D, Arko C, Chen SC, Daniels F, Ebben J, Frazier E, Johnson R, Sheets D, Wang X, Forrest B, Berrini D, Constantini E, Everson S, Eggers P, Agodoa L: US renal data system 2013 annual data report. Am J Kidney Dis 2014;63(1 suppl):A7.

30 Hung AM, Hakim RM: Dialysate and serum potassium in hemodialysis. Am J Kidney Dis 2015;66:125-132.

31 Zhang H, Schaubel DE, Kalbfleisch JD, BraggGresham JL, Robinson BM, Pisoni RL, Canaud B, Jadoul M, Akiba T, Saito A, Port FK, Saran R: Dialysis outcomes and analysis of practice patterns suggests the dialysis schedule affects day-of-week mortality. Kidney Int 2012;81:1108-1115.

32 Esposito C, Bellotti N, Fasoli G, Foschi A, Plati AR, Dal Canton A: Hyperkalemia induced ECG abnormalities in patients with reduced renal function. Clin Nephrol 2004;62:465-468.

33 Yusuf AA, Weinhandl ED, St Peter WL: Comparative effectiveness of calcium acetate and sevelamer on clinical outcomes in elderly hemodialysis patients enrolled in Medicare part D. Am J Kidney Dis 2014;64:95-103. 